\title{
Broken Tip of Meniscal Repair Instrument, Removed from the Back of the Knee 15 Months Postoperatively
}

\section{Ioannis C Vossinakis ${ }^{1 *}$ and Christos I Vosinakis ${ }^{2}$}

${ }^{1}$ Head of Orthopaedic Department, "ANASSA" Private Hospital, Volos, Greece ${ }^{2}$ Clinical Fellow, A\&E Department, Harrogate District Hospital, Harrogate, UK

*Corresponding Author: Ioannis C Vossinakis, Head of Orthopaedic Department, "ANASSA" Private Hospital, Volos, Greece.
Received: November 19, 2021

Published: December 29, 2021

(C) All rights are reserved by Ioannis C

Vossinakis and Christos I Vosinakis.

\begin{abstract}
Arthroscopic knee surgery is considered to be safe. A recent large study reported a $1.1 \%$ risk of complications, although earlier reports had significantly higher numbers, up to $8 \%$. Complications are more common with ACL reconstruction, meniscal repair and meniscectomy. One of the most common complications is the breakage of arthroscopic instruments into the joint. Most of them are identified and dealt with intraoperatively, sometimes with the aid of fluoroscopy. In some occasions, however, the breakage is not noticed during surgery and the broken instrument part is seen in postoperative radiographs. Some authors recommend immediate removal of foreign bodies, especially sharp ones, while others tend to leave those in place if they are asymptomatic. We present a broken tip of an all-inside meniscal repair instrument that remained undetected during surgery, and was eventually removed 15 months postoperatively, when it became symptomatic. To our knowledge, such a case has not been previously reported in the literature.
\end{abstract}

Keywords: Knee Arthroscopy; Meniscal Repair; Instrument Breakage

\section{Introduction}

Arthroscopic knee surgery is safe and becoming safer with improved instrumentation and surgeon training [1]. Complication rates have decreased from approximately $8 \%$ in the old days to about $1.1 \%$ in recent studies [2,3]. They are more common with the more demanding procedures, like ACL reconstruction, meniscal repair and meniscectomy [2,4]. Instrument breakage is a fairly common complication, due to maneuvering in tight spaces without good visualisation sometimes [5,6]. Usually broken instrument bits are discovered and removed intraoperatively, sometimes with the aid of fluoroscopy [7]. However, in some cases, the broken part is not immediately seen and it is discovered on postoperative radiographs. In such case, some surgeons recommend immediate removal, especially if the foreign body is sharp, while others leave it in place provided it does not cause any symptoms [6]. We present a case of a broken tip of a meniscal repair instrument that went unnoticed until a postoperative X-ray was done. It was removed 15 months postoperatively when it became symptomatic due to migration subcutaneously. To our knowledge, such a case has not been previously reported in the literature. A recent book, with a chapter focusing on meniscal repair complications, mentions implant breakage and migration but no instrument breakage [8] .

\section{Case Report}

A 37 year old male patient had an arthroscopic ACL reconstruction and medial meniscal repair. For the ACL, a semitendinosusgracilis graft was used and was fixed with ToggleLoc ${ }^{\mathrm{TM}}$ Device in the femur and ComposiTCP ${ }^{\mathrm{TM}}$ Interference Screw in the tibia (Zimmer Biomet, Warsaw IN). The meniscal repair was performed before the ACL reconstruction using the JuggerStitch ${ }^{\text {TM }}$ Meniscal Repair Device (Zimmer Biomet, Warsaw IN). The first attempt failed due to suture pull-out and a second device was used with successful meniscal suturing. Following graft harvesting and preparation, the ACL reconstruction was performed; the knee was thoroughly washed out, the wounds closed and the leg bandaged. The postoperative period was uneventful and after appropriate rehabilitation the patient returned to full activities without any symptoms. On the postoperative radiograph a metallic sharp foreign body was evident posterior to the medial compartment [Figure 1]. It looked cannulated and was considered to be the tip of the meniscal repair 
device; however we could not confirm it, as the used devises had been safely discarded following the procedure. Since the patient was not complaining of any symptoms that could be attributed to the foreign body, it was decided to leave it in place. Fifteen months postoperatively the patient returned reporting swelling and pain at the popliteal fossa. On examination a mildly inflamed, hard and painful nodule was evident at the center of the fossa. New radiographs revealed the metallic object lying immediately subcutaneously at the respected area of the nodule, with the sharp end towards the back [Figure 2]. It became obvious that during that period it had migrated to that position, fortunately without any injury to the neurovascular elements of the fossa. It was easily removed under local anaesthesia [Figure 3] and the patient had an uneventful recovery, returning to full activities 2 weeks after removal.
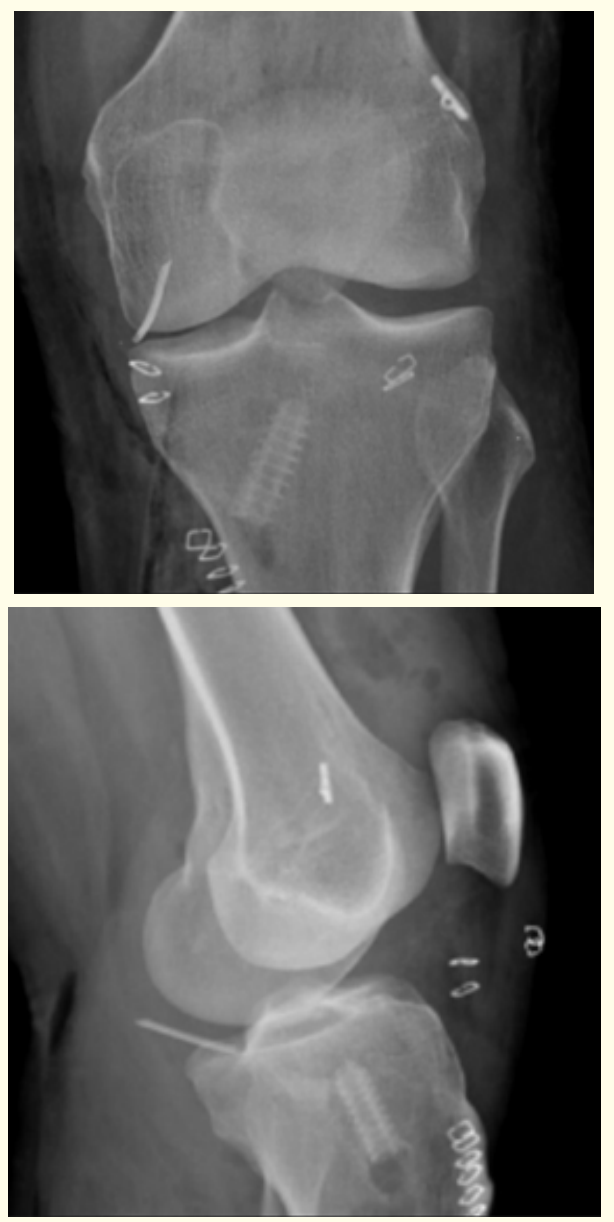

Figure 1: A, B: Postoperative radiographs showing a sharp, metal foreign body behind the medial compartment of the knee.
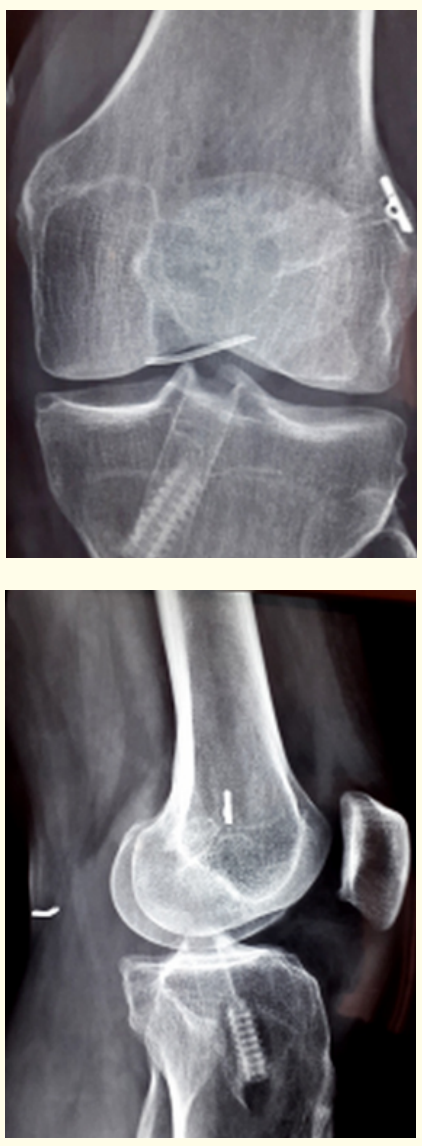

Figure 2: A, B: Radiographs at 15 months. The foreign body has migrated subcutaneously and has become symptomatic.

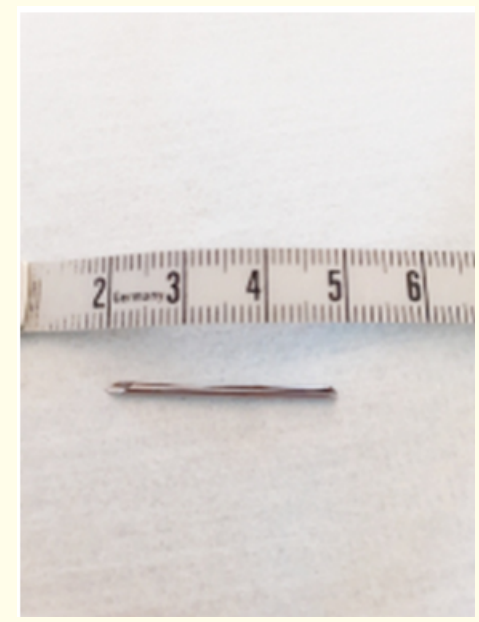

Figure 3: A $3 \mathrm{~cm}$ broken tip of the meniscal repair device was removed under local anaesthesia. 


\section{Discussion}

Broken instrument parts are a common mishap during arthroscopy $[3,5,6]$. They are usually discovered and removed intraoperatively [5]. Sometimes they migrate into difficult to access areas of the knee and require accessory portals or skin incisions and fluoroscopy [5,8]. Some surgeons elect to leave difficult to remove foreign objects in place provided they do not interfere with knee movement and don't cause any symptoms [6]. In our case, the breakage went unnoticed until the postoperative radiograph was taken. We suspect that it was the tip of the first meniscal suturing instrument that failed to deliver the suture. It probably broke into the meniscus, maybe from unintentional extension of the knee. While removing the instrument from the knee its tip was not observed because of the covering sheath and our preoccupation of using a new one for ultimately performing the meniscal repair. We believe that with the movements during ACL reconstruction, especially tensioning, the broken tip, with the sharp end already behind the meniscus, was pushed further back and eventually exited the knee and was embedded in the medial head of the gastrocnemius muscle. During the next months the normal activities of the patient kept pushing it towards the back of the knee until it reached the subcutaneous fat and started irritating the patient with a foreign body reaction.

\section{Conclusion}

Following this experience, we recommend that all instruments used during arthroscopy are carefully observed after their use, as a breakage might go unnoticed with the arthroscope. In case of suspicion, fluoroscopy would help identifying foreign bodies and removing them before they cause any damage. Sharp foreign bodies are known to migrate even to great distances. Although in our case the migration of this sharp metal did not cause any injury, this might not be the case every time. The popliteal fossa is an area with significant neurovascular structures that could be in great risk with similar foreign bodies.

\section{Conflict of Interest}

The authors declare that there is no conflict of interest, or any financial support for this manuscript.

\section{Bibliography}

1. Hagino T., et al. "Complications after arthroscopic knee surgery". Archives of Orthopaedic and Trauma Surgery 134.11 (2014): 1561-1564.

2. Jameson SS., et al. "The burden of arthroscopy of the knee: a contemporary analysis of data from the English NHS". Journal of Bone and Joint Surgery British 93.10 (2011): 1327-1333.
3. Friberger Pajalic et al. "Update on the risks of complications after knee arthroscopy". BMC, Musculoskeletal Disorders 19 (2018): 179.

4. Salzler MJ., et al. "Complications after arthroscopic knee surgery”. American Journal of Sports Medicine 42.2 (2014): 292296.

5. Milankov M., et al. "Broken Blade in the Knee: A Complication of Arthroscopic Meniscectomy". Arthroscopy: The Journal of Arthroscopic and Related Surgery 18.1 (2002): E4.

6. Oztekin HH. "An unusual complication of knee arthroscopy: An extra-articular migrated asymptomatic broken probe from the knee joint". Archives of Orthopaedic and Trauma Surgery 125 (2005): 285-287.

7. Prasataporn N., et al. "Arthroscopic and Fluoroscopic Guidance Removal of Intratendinous Broken Instrument During Rotator Cuff Repair". Arthroscopy Techniques 8.10 (2019): e1111-e1114.

8. Graveleau N., et al. "Meniscal Repair: Intra and Postoperative Complications". in C. Hulet., et al. (eds.), Surgery of the Meniscus. Springer, Berlin, Heidelberg. ESSKA (2016): 333-341.

\section{Assets from publication with us}

- Prompt Acknowledgement after receiving the article

- Thorough Double blinded peer review

- Rapid Publication

- Issue of Publication Certificate

- High visibility of your Published work

Website: www.actascientific.com/

Submit Article: www.actascientific.com/submission.php

Email us: editor@actascientific.com

Contact us: +919182824667 